\title{
FUNDAMENTOS DA INTERNACIONALIZAÇÃO DO DIREITO DO TRABALHO
}

\author{
João Carlos Casella \\ Professor Assistente do Departamento de Direito do Trabalho da \\ Faculdade de Direito da Universidade de São Paulo
}

\begin{abstract}
Resumo:
O receio de encarecer seus produtos e perder a concorrência para outras empresas ou países determinou que o nascimento e desenvolvimento do Direito do Trabalho dependesse, internamente, de generalização e, externamente, da internacionalização de suas regras. A esse fundamento de ordem econômica (concorrência internacional) somam-se outros, de ordem política (como a paz universal) e de ordem social (como a justiça social). Os três fundamentos são importantes mas, atualmente, é o anseio de realizar a justiça social que predomina, dificultado pelo grande desnível econômico que existe entre países desenvolvidos e países subdesenvolvidos. Daí ser indispensável uma ação internacional no sentido de estabelecer uma nova ordem econômica mundial.
\end{abstract}

\begin{abstract}
:
The concern in not making one's products more expensive and losing the competition with other companies and countries made the birth and development of Labor Law depend internally on the generalization and externally on the internalization of its rules. Other elements of a political nature (such as universal peace) and of a social nature (such as social justice) are added to this economic element (international competition). The three elements are important but at present it is the desire to warrant social justice that prevails, hampered by the great economic differences existing between the developed and the undeveloped countries. This makes it necessary for international action to be taken to establish a new world economic order.
\end{abstract}

Desde suas origens o Direito do Trabalho possui "nota de universalidade". como afirma Evaristo de Moraes Filho. ${ }^{1}$

Esse caráter universal é explicado pelas mesmas razões "políticas, econômicas, sociológicas e filosóficas" que determinam seu desenvolvimento. ${ }^{2}$

1. Introdução ao Direito do Trabalho, $2^{\mathrm{a}}$ ed, São Paulo, Ltr., 1978, p. 173; Wagner Giglio, a seu turno, alude à "vocação internacional" do Direito do Trabalho, com igual sentido (O.I.T. e Convenções Internacionais do Trabalho Ratificadas pelo Brasil, São Paulo, Sugestões Literárias, p. 19, 1973).

2. Giglio, Wagner, ob. cit., p. 19. 
A aplicação da filosofia liberal-individualista às relações de trabalho formadas sob o impacto da Revolução Industrial, que desequilibrou o mercado de trabalho em prejuízo dos trabalhadores, conduziu à imposição, pelos empregadores, "das mais vís condições de trabalho que a história registra" 3

De um lado, mesmo tendo consciência de que a melhoria das condições de vida, de trabalho e de remuneração dos trabalhadores ensejariam benefícios econômicos importantes (melhoria na produção; redução dos efeitos danosos da greve), os empregadores relutavam em fazer concessões temendo que, não-generalizadas, ficariam em desvantagem em relação à concorrência, que seguiria produzindo a custos inferiores. ${ }^{4}$

Assim, a pretensão à generalização das eventuais concessões aos trabalhadores representava, a um só tempo, um obstáculo para sua implementação (ante o temor à concorrência) e um estímulo à mesma (na medida em que a pregação pela generalização incluía a aceitação, pelos empresários, de tais concessões).

Por outro lado, tal situação não era um fenômeno localizado já que o modo de produção, com a adoção dos mesmos meios tecnológicos e da mesma forma de organização do trabalho, era igual em diversos países, circunstância que produzia idênticos problemas a requerer iguais soluções. Também o intercâmbio de trabalhadores, facilitado pela evolução dos transportes e comunicações, contribuía para a disseminação de idênticas preocupaçð̃es. ${ }^{5}$

Vê-se, assim, que a generalização antes referida na verdade tinha dimensão maior, na medida em que ultrapassava fronteiras nacionais, demonstrando o caráter universal do problema e, em conseqüência, da busca de sua solução.

Como bem observa Wagner Giglio, os trabalhadores não demoraram a perceber essa indivisibilidade do problema a recomendar sua união, à margem de fronteiras: "... a melhoria de tratamento em qualquer país ensejava-lhes reivindicar iguais beneficios" "Essa circunstância, somada ao interesse dos empregadores em evitar conturbações sociais capazes de interferir na produção, viabilizado se generalizadas as concessões, fez do foro internacional o palco adequado para o estudo e debate da situação dos trabalhadores e suas reivindicações. 1986.

3. Sussekind, Arnaldo Lopes, Direito Internacional do Trabalho, $2^{\mathrm{a}}$ ed., São Paulo, Ltr., p. 82,

4. Giglio, Wagner, ob. cit., p. 19.

5. Moraes Filho, Evaristo de, ob. cit., p. 173.

6. Ob. cit., p. 19. 
Firmou-se, assim, o caráter universal do Direito do Trabalho, então em elaboração. O empenho era no sentido de obter soluções em todos os locais onde o problema existisse, ainda que tais soluções fossem alcançadas independentemente umas das outras, por estes ou aqueles países.

Paulatinamente, os Estados foram abandonando a postura liberal que adotavam frente à questão social e, sensíveis aos apelos de pensadores da época, de diversas áreas do conhecimento e de diferentes ideologias, passaram a intervir nas relações de trabalho.

Essa postura intervencionista dos Estados fê-los interessados diretos na questão trabalhista na medida em que, se de um lado resolviam a questão social, internamente, de outro poderiam estar criando encargos maiores para seus empresários e, com isso, opondo-lhes dificuldades na concorrência internacional, com reflexos negativos para a economia nacional.

Tal preocupação haveria de levá-los a buscar compromissos recíprocos com outros países, através de tratados internacionais ${ }^{7}$ e, mais adiante, da instituição de organismos internacionais permanentes.

Já aqui, pois, não se está perante a simples universalidade do Direito do Trabalho, mas, sim, diante de sua internacionalização. Aquela - concebida como uma ampliação, para além-fronteiras, da generalização que marcou o Direito do Trabalho desde seu início - não se confunde com esta, concebida como um compromisso entre Estados acerca das relações de trabalho.

Para realçar essa distinção pode-se valer da invocação que Evaristo de Moraes Filho faz do conceito de Direito Internacional do Trabalho de Troclet, a saber: “... parte do direito internacional que regula as relações dos Estados entre si, tendo em vista os nacionais considerados como trabalhadores atuais, futuros ou ex-trabalhadores" 8

A internacionalização do Direito do Trabalho não se resumia a uma simples harmonização de legislações nacionais preexistentes, para facilitar transações internacionais. Ao contrário, foi considerada “... como uma condição indispensável à existência mesma, à preservação e ao desenvolvimento de legislações nacionais" 9

7. Giglio, Wagner, ob. cit., p. 20.

8. Ob. cit., p. 173 - os grifos e os destaques não constam do original.

9. Valticos, Nicolas, Droit International du Travail, in Traité de Droit du Travail (dir. G.H. Camerlynck), t. VIII, Paris, Dalloz, p. 3, 1970. 
Sua importância pode ser avaliada à luz da seguinte ponderação de Nicolas Valticos: Enfim, firmara-se fortemente a idéia de que a Legislação do trabalho seria internacional ou não seria. ${ }^{10}$

Os fundamentos genéricos da internacionalização do Direito do Trabalho a rigor confundem-se com os próprios fundamentos deste, como assinala Wagner Giglio." Especificamente, porém, vale destacar a concorrência internacional, a paz universal e a justiça social. ${ }^{12}$

$\mathrm{O}$ realce dado ao fundamento de ordem econômica - a concorrência internacional - justifica-se quando menos sob o prisma histórico.

Como assinala a doutrina, um dos grandes entraves à adoção de normas de proteção ao trabalho, pelos Estados, residia no temor a uma situação desvantajosa na concorrência internacional. É que, adotada tal proteção, determinado país industrializado estaria, ipso facto, onerando seus produtores-empregadores e, em conseqüência, provocando uma majoração no preço dos produtos. Ora, na medida em que produtores-empregadores de outros países não estivessem sujeitos a ônus iguais (e pudessem seguir pagando salários ínfimos a seus empregados e deles exigindo jornadas alongadas) é evidente que estes poderiam oferecer seus produtos a preços melhores no mercado internacional em relação àqueles. Tal situação de desvantagem afetaria diretamente os empregadores e, de maneira reflexa, os próprios Estados.

Dessa forma, a adoção de normas de caráter internacional teria a virtude de eliminar esse obstáculo, funcionando como uma espécie de "código de concorrência leal" e de vencer as resistências internas à adoção de normas de proteção ao trabalho pela subtração do principal argumento de seus opositores. ${ }^{13}$

Não é possível negar a importância decisiva que teve esse argumento para a internacionalização do Direito do Trabalho e, pois, para o próprio Direito do Trabalho. Entretanto, é certo também que, com o correr do tempo, a internacionalização do Direito do Trabalho passou a encontrar amparo mais acentuado em outras razões, minimizando-se a importância do fundamento econômico aqui exposto.

10. Ob. cit., p. 3 - os destaques năo constam do original.

11. Ob. cit., p. 19.

12. Valticos, Nicolas, ob. cit., p. 113.

13. Idem, ibidem, p. 114. 
Essa mudança de enfoque - que Nicolas Valticos localiza em torno de $1904^{14}$ - decorreu da verificação de que muitos países industrializados haviam editado as primeiras leis trabalhistas independentemente de qualquer internacionalização, malgrado possibilitadas por algum avanço tecnológico significativo ou por algum tipo de proteção aduaneira. Outrossim, verificou-se também que os encargos decorrentes da legislação trabalhista eram apenas um dos muitos fatores que contribuíram para a formação do preço final dos produtos. ${ }^{15}$

Todavia, como em alguns países o argumento da concorrência internacional continuava a ser invocado pelos adversários da adoção de uma legislação trabalhista, surgiu a tese de que, se a internacionalização do Direito do Trabalho não era mais uma condição da existência de leis nacionais era, porém, um fator de contribuição para seu desenvolvimento. ${ }^{16}$

Foi com essa nova roupagem que esse argumento permaneceu no espírito das organizações e pessoas durante a Primeira Grande Guerra e ao seu final. Reflexo disso é que o argumento da concorrência internacional tem lugar na Parte XIII do Tratado de Versalhes, mas apenas em terceiro lugar. ${ }^{17}$

À vista de tais circunstâncias, Nicolas Valticos conclui que “... a idéia da concorrência internacional deixava de ser o argumento essencial", conservando, porém, “... um certo peso" 18

A partir da constituição da OIT, esse argumento chegou a ser invocado em algumas ocasiões e para finalidades específicas. Todavia, sua importância vem decrescendo paulatinamente. ${ }^{19}$

Hoje, a relevância desse argumento, embora presente, é reduzido, uma vez que o peso da legislação trabalhista nacional ou internacional nos custos da produção não incide automaticamente sobre o caráter competitivo de uma indústria, tanto porque há vários outros fatores que influem em sua composição como, também, porque podem ser compensados por maior e melhor produtividade da mão-

14. Idem, ibidem, p. 114.

15. Idem, ibidem, p. 114-5.

16. Idem, ibidem, p. 115.

17. Idem, ibidem, p. 115.

18. Idem, ibidem, p. 116.

19. V. Valticos, Nicolas, ob. cit., p. 116-7. 
de-obra, repercutindo, apenas, nas relações entre países em que essas outras condições são semelhantes. $^{20}$

Outros fundamentos da internacionalização do Direito do Trabalho foram lembrados ao longo do tempo. A parte XIII do Tratado de Versalhes refere-se, sucessivamente, ao argumento de ordem política (a paz mundial), ao argumento de ordem social (a necessidade de justiça social) e ao argumento de ordem econômica (concorrência internacional).

A percepção de que as privações e a miséria advindas das péssimas condições de trabalho colocavam em risco a paz mundial ficou patente durante a Primeira Grande Guerra Mundial, a tal ponto que foi a primeira das razões invocadas no Tratado de Versalhes. É certo que os conflitos internacionais não têm por causa principal essa situação injusta, predominando outros fatores. Mas é certo, também, que não há como estabelecer uma paz duradoura senão com base na justiça social, como significativamente se inseriu na Constituição da OIT na Declaração de Filadélfia, de 1944.

O argumento de ordem social - isto é, a melhoria da condição humana, a realização da justiça - estivera presente já nos primórdios da internacionalização do Direito do Trabalho, suscitando o apelo de políticos e pensadores da época no sentido de uma intervenção dos Estados e da comunidade internacional no plano dessas relações e foi expressamente consignado no Tratado de Versalhes, como visto. ${ }^{21}$ Seu conteúdo não se resume em eliminar a injustiça social, mas alcança o propósito de proporcionar o progresso material e espiritual do ser humano. $^{22}$

Esse propósito de padronização internacional da melhoria das condições sociais tem sido obstado pelo grave desequilíbrio econômico que se verifica entre países desenvolvidos e países subdesenvolvidos. A própria ação normativa da OIT tem sido prejudicada por isso: suas regras tendem a uma maior generalidade para conciliar as diferenças entre os países, cada vez mais acentuadas. ${ }^{23}$

20. Idem, ibidem, p. 118 .

21. Essa declaração solene representou uma grande inovação no Direito Internacional, em 1919, transformando o Homem em sujeito de Direito Internacional, circunstância capaz de explicar a razão da anterior preferência pela invocação dos outros argumentos (Valticos, Nicolas, ob. cit., p. 126-7).

22. Valticos, Nicolas, ob. cit., p. 128.

23. Sussekind, Arnaldo L., ob. cit., p. 29-30. 
Em virtude disso, grande parte da população acha-se à margem da justiça social, o que tem levado a OIT a concitar os países a que estabeleçam uma nova ordem econômica em bases justas e equitativas. ${ }^{24}$ Só assim seria possível chegar a um "contrato de solidariedade" entre os países, ensejando a melhoria da condição social dos trabalhadores. ${ }^{25}$

Como é possível ver, diferentes são os fundamentos da internacionalização do Direito do Trabalho ${ }^{26} \mathrm{e}$, bem assim, diferentes as épocas em que surgiram e o peso e a nuance de cada qual, ao longo do tempo.

$\mathrm{O}$ fundamento de ordem econômica - a concorrência internacional teve um peso decisivo em seu início, conserva sua influência até hoje, mas sua relevância acha-se minimizada.

$\mathrm{Na}$ verdade, a questão econômica, hoje, é outra. O brutal desequilíbrio entre países desenvolvidos e países subdesenvolvidos é que determina a existência de condições de grave injustiça social nestes últimos e requer a solução desta - pela simples razão de que é preciso melhorar a condição social de três quintos da força de trabalho mundial, que vive nessas condiçø̃es ${ }^{27}$ - mercê de uma ação internacional no sentido do estabelecimento de uma nova ordem econômica.

24. Idem, ibidem, p. 32-33.

25. Idem, ibidem, p. 32.

26. Nicolas Valticos também coloca dentre tais fundamentos a necessidade de uma política social acompanhada de uma regulamentação técnica precisa; a ação por um desenvolvimento econômico e social equilibrado; a regulamentação de situaçðes em que intervém um elemento internacional; a consolidação de legislą̧ððes nacionais; o parâmetro para as leis nacionais (ob. cit., p. 129-37). Montoya Melgar, A., também alude a fundamentos semelhantes (Derecho del Trabajo, $8^{\mathrm{a}}$ ed., Madrid, Tecnos, p. 192, 1987).

27. Sussekind, Arnaldo L., ob. cit., p. 33. 